\title{
On-demand cold plasma activation of acetyl donors for bacteria and virus decontamination
}

\author{
Endre J. Szili ${ }^{1^{*}}$, Bhagirath Ghimire ${ }^{\dagger 2}$, Bethany Lee Patenall ${ }^{3}$, Mohammed \\ Rohaim $^{4}$, Dharmit Mistry ${ }^{5}$, Adrian Fellows ${ }^{5}$, Muhammad Munir ${ }^{4}$, A. T. A. \\ Jenkins $^{3}$, Robert D. Short ${ }^{1,2 *}$ \\ ${ }^{1}$ Future Industries Institute, University of South Australia, Adelaide SA 5095, Australia \\ ${ }^{2}$ Department of Chemistry and Material Science Institute, Lancaster LA1 4YB, United Kingdom \\ ${ }^{3}$ Department of Chemistry, University of Bath BA2 7AY, United Kingdom \\ ${ }^{4}$ Division of Biomedical and Life Sciences, Lancaster University, LA1 4YW, United Kingdom \\ ${ }^{5}$ AGA Nanotech Ltd., 2 Regal Way, Watford Hertfordshire WD24 4YJ, United Kingdom
}

Antibiotics are commonly used as the first line of defense in the treatment of infectious diseases. However, the rise of antimicrobial resistance (AMR) is rendering many antibiotics less effective. Consequently, effective non-antibiotic antimicrobial strategies are urgently needed to combat AMR. This paper presents a strategy utilizing cold plasma for the "on-demand" activation of acetyl donor molecules. The process generates an aqueous-based antimicrobial formulation comprising a rich mixture of highly oxidizing molecules: peracetic acid, hydrogen peroxide and other reactive oxygen and nitrogen species. The synergistic potent oxidative action between these molecules is shown to be highly effective at eradicating common wound pathogenic bacteria (Pseudomonas aeruginosa and Staphylococcus aureus) and at inactivating a virus (SARS-CoV-2).

Antimicrobials are the most widely used therapeutic drugs worldwide. They have revolutionised medicine, farming and agriculture, and veterinary care, and are used in many other industries including commercial paint formulations. However, their overuse, particularly in the case of antibiotics, has rendered them less effective through the rise of antimicrobial resistance $(\mathrm{AMR})^{1}$. By 2050 , AMR is forecasted to cause 10M deaths per annum resulting in a potential US\$100 trillion shock to the global economy ${ }^{2}$. Consequently, there is a need for "on demand" antibiotic-free solutions for microbial eradication to eliminate the growing problem of AMR in healthcare and in our environment.

\footnotetext{
$\dagger$ Equal co-first authors

*Authors to whom correspondence should be addressed: Endre Szili endre.szili@unisa.edu.au and Robert Short r.d.short1@lancaster.ac.uk
} 
This study describes an antibiotic-free strategy utilising the cold plasma activation of acetyl donor antimicrobial precursors. The process generates a potent antimicrobial water-based disinfectant (Figure 1). Cold plasma is a low-temperature (e.g. human tissue tolerable) electrically-generated partially ionised glow-discharge. When operated into air, cold plasma activates the surrounding oxygen, nitrogen and water vapor molecules, generating reactive oxygen and nitrogen species (RONS) ${ }^{3-7}$. These RONS can oxidise molecules and cells which is potentially useful for a broad range of applications including water purification, sterilization and decontamination of pathogenic microorganisms ${ }^{8}$. Some of these RONS have a high Henry's law constant such as hydrogen peroxide $\left(\mathrm{H}_{2} \mathrm{O}_{2}\right)=1.92 \times 10^{6}$ and peroxynitrous acid $(\mathrm{ONOOH})=4.8$ x $10^{6}$ allowing for them to be easily solubilised when delivered by cold plasma into aqueous solutions (e.g. water) ${ }^{9}$. In combination, $\mathrm{H}_{2} \mathrm{O}_{2}$ and $\mathrm{ONOOH}$ can kill microorganisms through

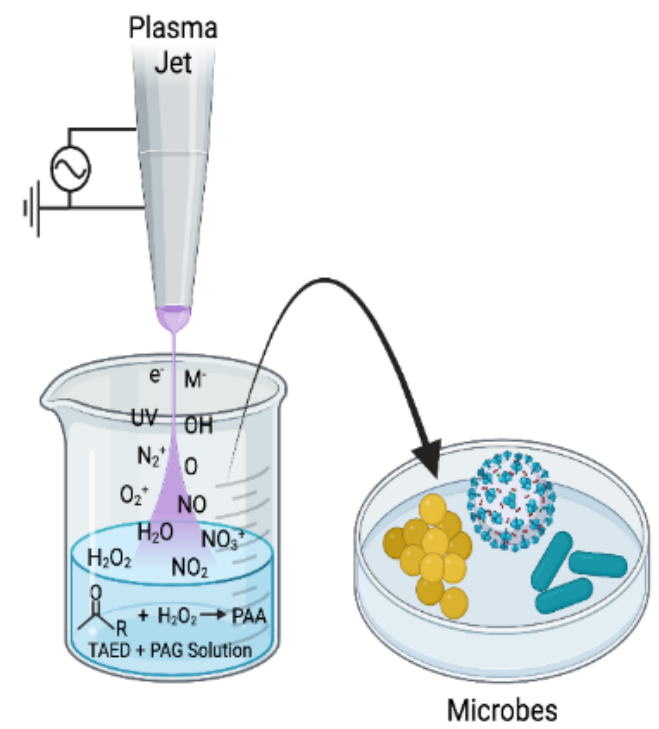

Figure 1: Pictorial overview of the cold plasma activation of an acetyl donor from TAED and PAG generating PAA, $\mathrm{H}_{2} \mathrm{O}_{2}$ and other RONS for the eradication of pathogenic microbes.

oxidative stress, exacerbated at low $\mathrm{pH}^{10-12}$. However, many microorganisms have efficient antioxidant defence mechanisms that reduce the antimicrobial efficacy of cold plasma, including certain pathogenic bacteria which can release catalase - an antioxidant enzyme that neutralises $\mathrm{H}_{2} \mathrm{O}_{2}{ }^{13}$. To mitigate this likely problem, we investigated the use of two antimicrobial precursor acetyl donors, tetraacetylethlynediamine (TAED) and pentaacetate glucose (PAG), to amplify the antimicrobial effects of cold plasma. TAED and PAG and their by-products are readily biodegradable and are non-toxic if used at low concentrations and can be manufactured using green 
chemistry ${ }^{14-16}$. Plasma generated $\mathrm{H}_{2} \mathrm{O}_{2}$ reacts with the acetyl donors of TAED and PAG to produce peracetic acid (PAA) which acts in synergy with $\mathrm{H}_{2} \mathrm{O}_{2}$ and other plasma generated RONS, providing a potent broad-spectrum antimicrobial solution (Figure 1). PAA at the low concentration used in this study, has been shown to be non-toxic in an animal model ${ }^{15}$. Further, PAA does not easily give rise to $\mathrm{AMR}^{15}$ and is used in many industrial applications including food decontamination ${ }^{17}$, wastewater treatment ${ }^{18}$, hospital waste sterilisation ${ }^{19}$ and medical instrument disinfection ${ }^{20}$. An advantage of PAA for these applications is that it does not leave harmful residues as it quickly decomposes to acetic acid, oxygen and water.

The cold plasma jet used for these experiments consisted of an internal stainless steel pin high voltage (HV) electrode sealed inside a quartz tube (inner diameter (ID) $=1.5 \mathrm{~mm}$, outer diameter $(\mathrm{OD})=3 \mathrm{~mm}$ ). Two cylindrical ground electrodes made up of copper were placed at positions of $56 \mathrm{~mm}$ and $110 \mathrm{~mm}$ below the tip of the HV electrode (Figure 2(a)). The first ground electrode helped to reduce the breakdown voltage while the second ground electrode served to increase the length of the plasma jet. The tube length of $164 \mathrm{~mm}$ below the HV electrode was designed to maximize the production of $\mathrm{H}_{2} \mathrm{O}_{2}{ }^{21}$. Plasma was ignited by purging $\mathrm{Ar}$ gas at 1 standard litres per minute through the tube and supplying $2.38 \mathrm{kV} \mathrm{rms}$ voltage at $23.5 \mathrm{kHz}$ to the HV electrode producing a dissipated power of $2.71 \mathrm{~W}$ (Figure 2(b), also see Supplementary
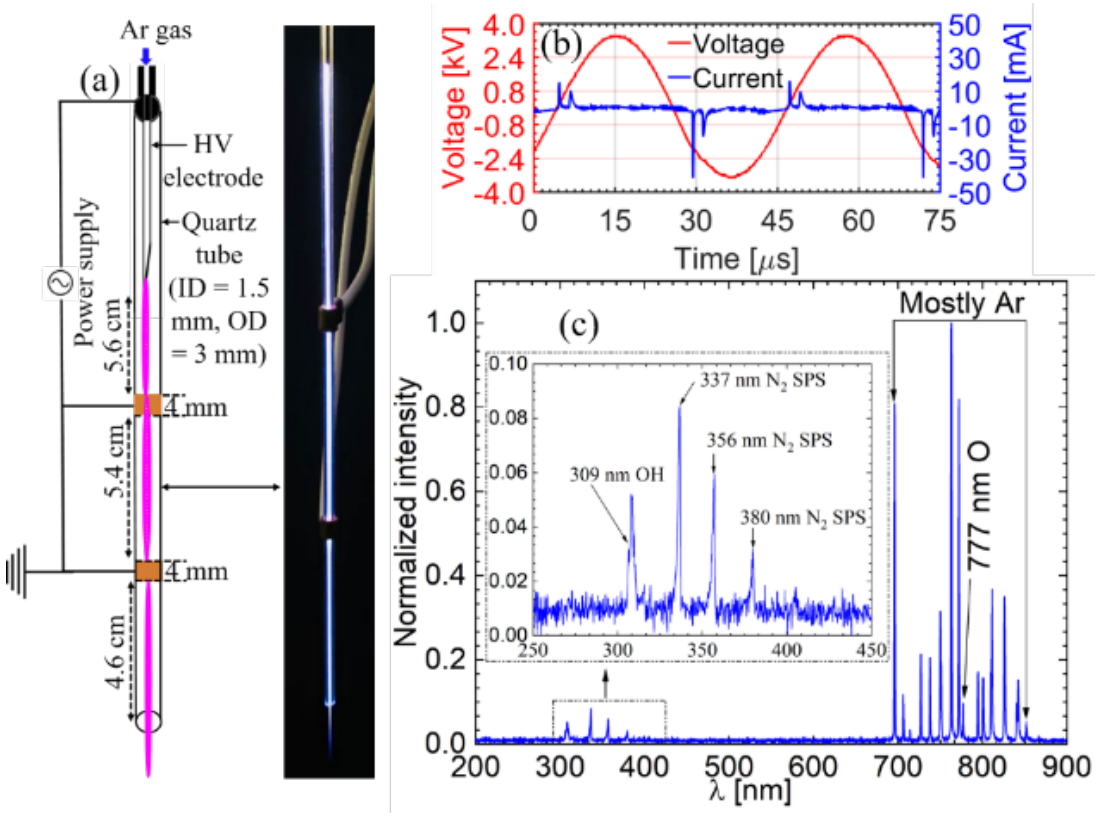

Figure 2: (a) Setup of the cold plasma jet assembly, (b) its current-voltage waveforms, and (c) optical emission spectra of the plasma discharge. 


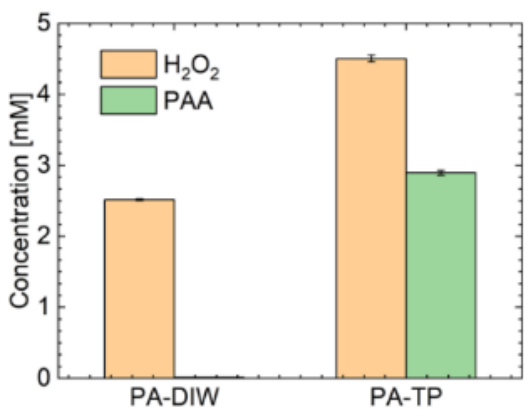

Figure 3: Concentration of $\mathrm{H}_{2} \mathrm{O}_{2}$ and PAA in the PA-DIW and PA-TP.

Information S1). Under the prescribed conditions, a plasma jet extends out of the tube to a distance of $\sim 14 \mathrm{~mm}$ (Figure 2(a)) with an optical emission typical of highly reactive species that form RONS through downstream reactions (Figure 2(c) and Supplementary material S2). The average gas temperature $\left(\mathrm{T}_{\mathrm{g}}\right)$ of the plasma jet (measured with an infrared thermometer, Fluke 62 Max) was found to be cool at $310.5 \pm 3.5 \mathrm{~K}$ at $4 \mathrm{~mm}$ position outside of the tube's orifice (i.e. at the same position as the liquid targets). Optical emission spectra shown in Figure 2(c) was used to estimate the electron temperature $\left(T_{e}\right)$ and vibrational temperature $\left(T_{v}\right)$ of the plasma jet. $T_{e}$ was calculated using collisional-radiative model $^{22}$ while $\mathrm{T}_{\mathrm{v}}$ was derived from the Boltzmann plot by analyzing the spectral bands of the nitrogen second positive system ${ }^{23}$. The values of $T_{e}$ and $T_{V}$ for the plasma jet were found to be $0.73 \mathrm{eV}$ and $2323 \mathrm{~K}$, respectively. A high value of electron temperature as compared to relatively lower values of ion and neutral gas temperature (i.e. $\mathrm{T}_{\mathrm{e}}>>\mathrm{T}_{\mathrm{v}}>>\mathrm{T}_{\mathrm{g}}$ ) verifies the non-thermal characteristics of the plasma jet. A mixture of $2.5 \mathrm{mM}$ TAED with $2.5 \mathrm{mM}$ PAG in $350 \mu \mathrm{L}$ deionised water (DIW) was used as the antimicrobial precursor because this blended system was previously shown to produce the optimal antimicrobial efficacy compared to the molecules used alone ${ }^{24}$. The antimicrobial efficacy of the plasma activated TAED-PAG (PA-TP) was compared to plasma activated DIW (PA-DIW) produced under the same plasma conditions. Statistical analysis was performed using a two-sample student $t$-test of unequal variance considering a $p<0.05$ as significant.

The major longer-lived antibacterial agents in PA-TP are $\mathrm{H}_{2} \mathrm{O}_{2}$ and PAA. Figure 3 (and Supplementary material S3) show the concentration of $\mathrm{H}_{2} \mathrm{O}_{2}$ and PAA in PA-TP were $4.5 \mathrm{mM}$ and 2.9mM, respectively. PA-DIW had a slightly lower $\mathrm{H}_{2} \mathrm{O}_{2}$ concentration at $2.5 \mathrm{mM}$ and contained no PAA because of the absence of TAED and PAG. PA-TP was more acidic at $\mathrm{pH} 2$ compared to PA-DIW at $\mathrm{pH} 4$. 
Formation of $\mathrm{H}_{2} \mathrm{O}_{2}$ in PA-DIW and PA-TP is known to occur through several pathways. This mainly occurs through the formation of an intermittent product (hydroxyl radical, ${ }^{\circ} \mathrm{OH}$ ) through: $5,21,22$

(a) collisions with electrons: $\mathrm{e}-+\mathrm{H}_{2} \mathrm{O} \rightarrow \mathrm{H}+{ }^{\circ} \mathrm{OH}+\mathrm{e}^{-}$

(b) collisions with metastable atoms / radicals: $\mathrm{e}^{-}+\mathrm{O}_{2} \rightarrow \mathrm{O}\left({ }^{3} \mathrm{P}\right)+\mathrm{O}\left({ }^{1} \mathrm{D}\right)+\mathrm{e}^{-}, \mathrm{O}\left({ }^{1} \mathrm{D}\right)+\mathrm{H}_{2} \mathrm{O} \rightarrow$ $2^{\cdot} \mathrm{OH} ; \mathrm{e}^{-}+\mathrm{N}_{2} \rightarrow \mathrm{N}_{2}\left(\mathrm{~A}^{3} \Sigma_{\mathrm{u}}^{+}\right)+\mathrm{e}^{-}, \mathrm{N}_{2}\left(\mathrm{~A}^{3} \Sigma_{\mathrm{u}}^{+}\right)+\mathrm{H}_{2} \mathrm{O} \rightarrow{ }^{\circ} \mathrm{OH}+\mathrm{N}_{2}+\mathrm{H}$

(c) collisions with argon metastables: $\mathrm{e}^{-}+\mathrm{Ar} \rightarrow \mathrm{Ar}_{\mathrm{m}}+\mathrm{e}^{-}, \mathrm{Ar}_{\mathrm{m}}+\mathrm{H}_{2} \mathrm{O} \rightarrow \mathrm{Ar}+\mathrm{H}_{2} \mathrm{O}^{+}+\mathrm{e}^{-}$; $\mathrm{e}^{-}+$ $\mathrm{H}_{2} \mathrm{O}+\rightarrow \cdot \mathrm{OH}+\mathrm{H}$

(d) plasma initiated ultra-violet (UV) photolysis: $\mathrm{UV}+\mathrm{H}_{2} \mathrm{O} \rightarrow \mathrm{H}_{2} \mathrm{O}^{*}$; $\mathrm{UV}+\mathrm{H}_{2} \mathrm{O}^{*} \rightarrow \mathrm{H}^{+}+\mathrm{OH}^{-}$ $; \mathrm{OH}^{-} \rightarrow \cdot \mathrm{OH}+\mathrm{e}^{-}$.

'OH radicals formed through (a)-(d) subsequently recombine to form $\mathrm{H}_{2} \mathrm{O}_{2}$ as shown in the reaction: ${ }^{\circ} \mathrm{OH}+{ }^{\circ} \mathrm{OH} \rightarrow \mathrm{H}_{2} \mathrm{O}_{2}$. The plasma generated $\mathrm{H}_{2} \mathrm{O}_{2}$ molecules subsequently react with the acetyl donor-containing molecules to form PAA.

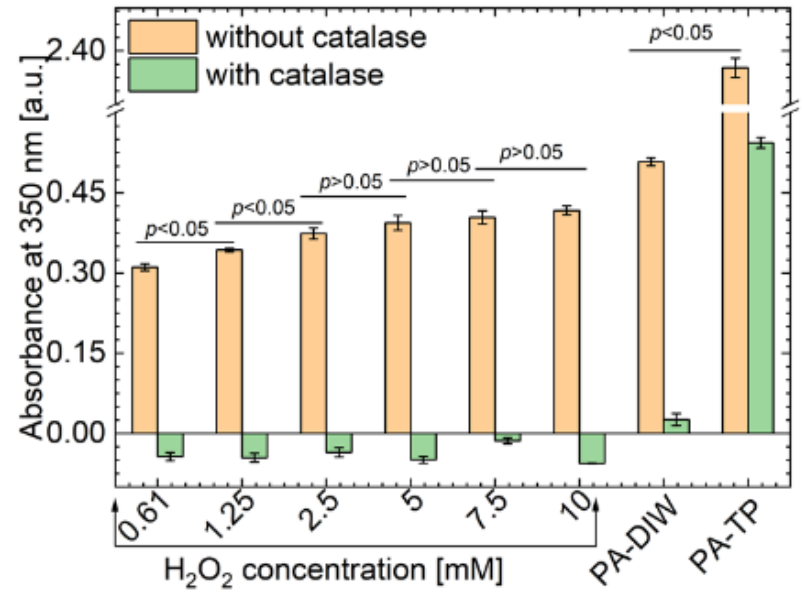

Figure 4: Oxidation of KI from varying concentrations of $\mathrm{H}_{2} \mathrm{O}_{2}$, PA-DIW and PA-TP with and without the presence of catalase.

In the next experiments, the oxidising capacity of PA-TP and PA-DIW compared to standard $\mathrm{H}_{2} \mathrm{O}_{2}$ solutions was tested through their ability to oxidise potassium iodide (KI, Supplementary material S3). The principle is based upon the oxidation of KI to produce triiodide ions with an absorbance maximum of $350 \mathrm{~nm}$. TAED-PAG alone (i.e. prior to plasma activation) produces zero absorbance reading at $350 \mathrm{~nm}$ indicating that it does not oxidise $\mathrm{KI}$ (due to the absence of oxidants). Figure 4 shows that $0.61-10 \mathrm{mM} \mathrm{H}_{2} \mathrm{O}_{2}$ solutions readily oxidise KI. A statistically identical level of $\mathrm{KI}$ oxidation was achieved with $2.5-5 \mathrm{mM} \mathrm{H}_{2} \mathrm{O}_{2}(p>0.05)$, indicating that the small differences in the $\mathrm{H}_{2} \mathrm{O}_{2}$ concentrations in PA-TP (4.5mM) and PA-DIW (2.9mM) 
should not be a major contributing factor to their oxidative capacity. A slightly higher level of KI oxidation was produced by PA-DIW (absorbance @ $350 \mathrm{~nm}=0.5$ ) compared to the equivalent $2.5 \mathrm{mM} \mathrm{H}_{2} \mathrm{O}_{2}$ standard solution (absorbance @ $350 \mathrm{~nm}=0.37$ ). This result is attributed to other RONS in the PA-DIW making a further small contribution to the oxidation of KI. PA-TP produced a significantly higher level of oxidised KI (absorbance @ $350 \mathrm{~nm}=2.4$ ) compared to PA-DIW ( $p$ $<0.05$ ) attributed to the synergistic oxidation of $\mathrm{KI}$ by PAA, $\mathrm{H}_{2} \mathrm{O}_{2}$ and other RONS.

The presence of $75 \mathrm{mg} / \mathrm{mL}$ catalase abolished the oxidative capacity of the standard $\mathrm{H}_{2} \mathrm{O}_{2}$ solutions and PA-DIW (Figure 4). This indicates that $\mathrm{H}_{2} \mathrm{O}_{2}$ was the major oxidant in PA-DIW. Conversely, catalase did not abrogate the oxidative capacity of PA-TP (absorbance @ $350 \mathrm{~nm}=$ 0.5). This result is attributed to the additional oxidant PAA (in PA-TP) that is not affected by the catalase.

Finally, the antimicrobial property of PA-TP and PA-DIW were assessed (Supplementary material S4). First assessment was carried out by examining their bactericidal action against common wound pathogens Gram-negative Pseudomonas aeruginosa (P. aeruginosa) and Grampositive Staphylococcus aureus (S. aureus) in planktonic state. Optical density (OD) measurement of the bacteria broth was used to assess bacterial growth. Figure 5(a) shows that the final OD measured in the P. aeruginosa culture following treatment with the PA-DIW was lower compared to the untreated bacteria positive control $(p<0.05)$ and the same as the sterile broth negative control $(p>0.05)$, indicating that PA-DIW significantly reduced the growth of the bacteria. However, PADIW was not bactericidal against $S$. aureus (Figure 5(a)), presumably due to its more complex Gram-positive membrane structure providing a barrier against the treatment. In comparison, PATP treatments decreased bacterial load for $P$. aeruginosa and $S$. aureus to an undetectable level ( $p$ $>0.05$ compared to the sterile broth). These results indicate that PA-TP is a more effective bactericidal agent compared to PA-DIW. Based on our protocols, the starting culture of $2 \times 10^{6}$ $\mathrm{CFU} / \mathrm{mL}$ used in this assay (Supplementary material S4) would equate to $\sim 10^{9} \mathrm{CFU} / \mathrm{mL}$, corresponding to an OD of $\sim 4$ for both bacteria. Therefore, we estimate that the results achieved with the PA-TP correspond to at least a $10^{6}-\log$ up to a maximum of $\sim 10^{9}-\log$ reduction in bacterial growth. Similar trends were observed when the virucidal activities of PA-TP and PA-DIW were tested against SARS-CoV-2 (Supplementary material S5). Figure 5(b) shows that the PA-DIW reduced the viral load by $50 \%$, whereas PA-TP achieved a greater reduction in viral load of $>84 \%$. 

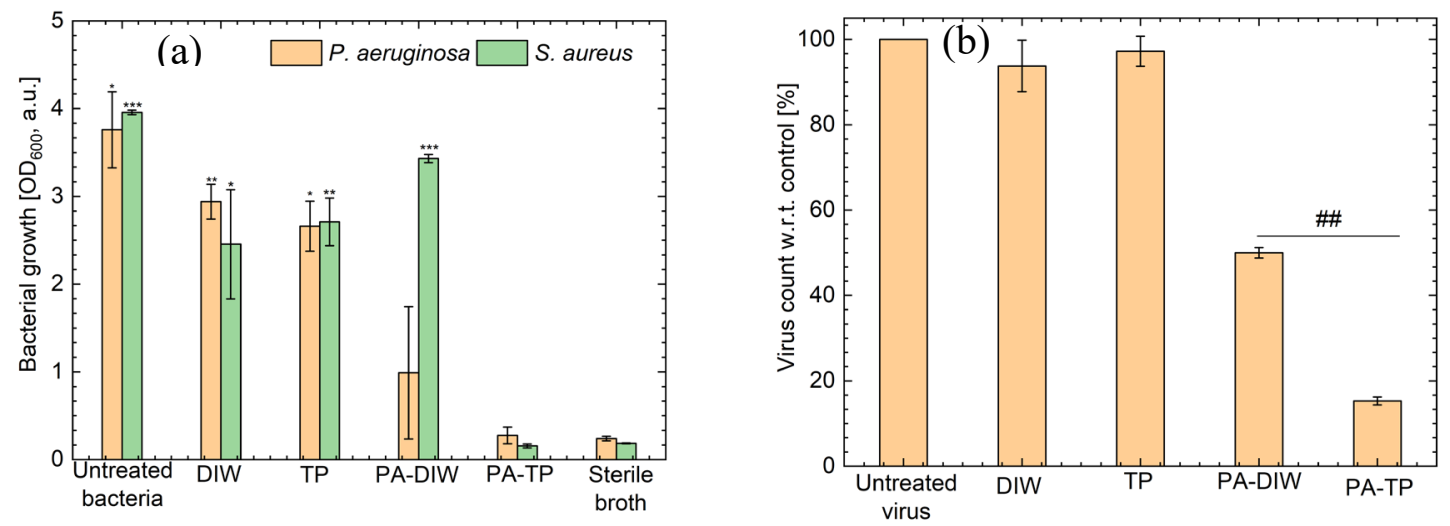

Figure 5: (a) Reduction in growth of $P$. aeruginosa and $S$. aureus by PA-DIW and PA-TP. Results were compared to untreated DIW and TP solutions. Positive control = Untreated bacteria; Negative control $=$ Sterile broth. Following treatment, bacteria were incubated in the test solutions for $18 \mathrm{~h}$. (b) Reduction in SARS-CoV-2 viral load by PA-DIW and PATP. Results were compared to untreated DIW and TP solutions and untreated virus as a positive control. The asterisk (*) symbols above the bars in 5(a) represent statistical significance compared to sterile broth (bacteria) with one symbol $p=0.01-0.05$, two symbols $p=0.001-0.01$ and three symbols $p<0.001$. The \# above PA-TP in 5(b) represents a statistical significance of $p<0.05$ compared to PA-DIW.

Importantly, neither the DIW nor the TP solutions alone (i.e. without plasma activation) were antimicrobial against the bacteria and the virus in Figures 5(a) and 5(b). This shows that the high antimicrobial activity of PA-TP is indeed attributed to the unique combination of the cold plasma jet treatment with TP, which is activated on-demand upon plasma ignition. The test solutions used in Figure 5 were diluted 4-fold (Supplementary material S5) and this was kept constant for both bacteria and virus assays. We anticipate that a more concentrate PA-TP solution would yield a higher level of virus inactivation.

Overall, this study demonstrates how the antimicrobial effects of cold plasma can be amplified with acetyl donor molecules. The acetyl donor formulation can be configured for ondemand use either in a liquid formulation as demonstrated in this study, or potentially in a cream or gel formulation, or even within a hydrogel wound dressing activated by a small hand-held cold plasma device. Major advantages of on-demand PA-TP for these applications include the ability to produce stable formulations with a long shelf-life and without the requirement of refrigeration, and its multipronged action coupled with on-demand activation prevents prolonged exposure of microorganisms to sub-optimal concentrations of the antibacterial agents; all of which are likely to help resist the development of AMR in healthcare and in our environment. 
See Supplementary material for measurement and calculation of cold plasma jet dissipated power (SI 1), optical emission spectrum from the cold plasma jet (SI 2), measurement of $\mathrm{H}_{2} \mathrm{O}_{2}$ and PAA after cold plasma activation of DIW/acetyl donors (SI 3), antibacterial assays (SI 4) and antiviral assays (SI 5).

The authors would like to thank the EPSRC for funding on Grant EP/R003556/1 and EP/V00607X/1). EJS acknowledges the support from the Australian Research Council Future Fellowship FT190100263, the National Health Medical Research Council Ideas Grant 2002510 and the Future Industries Accelerator Mobility Scheme MOB024. The data that supports the findings of this study are available within the article [and its supplementary material].

\section{References}

1. J. Davies and D. Davies, Microbiol. Mol. Biol. Rev., 1996, 74, 417-433.

2. J. O'Neil, Tackling drug-resistant infections globally: final report and recommendations, 2016.

3. A. Khlyustova, C. Labay, Z. Machala, M. P. Ginebra and C. Canal, Front. Chem. Sci. Eng., 2019, 13, $238-252$.

4. T. Von Woedtke, S. Emmert, H. R. Metelmann, S. Rupf and K. D. Weltmann, Phys. Plasmas, 2020, 27, 070601:1-07060115.

5. B. Ghimire, E. J. Szili, P. Lamichhane, R. D. Short, J. S. Lim, P. Attri, K. Masur, K. D. Weltmann, S. H. Hong and E. H. Choi, Appl. Phys. Lett., 2019, 114, 093701:1-093701-6.

6. N. Gaur, E. J. Szili, J. S. Oh, S. H. Hong, A. Michelmore, D. B. Graves, A. Hatta and R. D. Short, Appl. Phys. Lett., 2015, 107, 103703:1-103703:5.

7. P. J. Bruggeman, M. J. Kushner, B. R. Locke, J. G. E. Gardeniers, W. G. Graham, D. B. Graves, R. C. H. M. HofmanCaris, D. Maric, J. P. Reid, E. Ceriani, D. Fernandez Rivas, J. E. Foster, S. C. Garrick, Y. Gorbanev, S. Hamaguchi, F. Iza, H. Jablonowski, E. Klimova, J. Kolb, F. Krcma, P. Lukes, Z. MacHala, I. Marinov, D. Mariotti, S. Mededovic Thagard, D. Minakata, E. C. Neyts, J. Pawlat, Z. L. Petrovic, R. Pflieger, S. Reuter, D. C. Schram, S. Schröter, M. Shiraiwa, B. Tarabová, P. A. Tsai, J. R. R. Verlet, T. Von Woedtke, K. R. Wilson, K. Yasui and G. Zvereva, Plasma Sources Sci. Technol., 2016, 25, 053002:1-053002:59.

8. A. Barjasteh, Z. Dehghani, P. Lamichhane, N. Kaushik and E. H. Choi, Appl. Sci., 2021, 11, 1-22.

9. W. Tian and M. J. Kushner, J. Phys. D. Appl. Phys., 2014, 47, 165201:1-165201:21.

10. S. Ikawa, K. Kitano and S. Hamaguchi, Plasma Process. Polym., 2010, 7, 33-42.

11. S. Ikawa, A. Tani, Y. Nakashima and K. Kitano, J. Phys. D. Appl. Phys., 2016, 49, 425401:1-425401:9.

12. P. Lukes, E. Dolezalova, I. Sisrova and M. Clupek, Plasma Sources Sci. Technol., 2014, 23, 015019:1-015019:15.

13. H. J. Hathaway, B. L. Patenall, N. T. Thet, A. C. Sedgwick, G. T. Williams, A. T. A. Jenkins, S. L. Allinson and R. D. Short, J. Phys. D. Appl. Phys., 2019, 52, 505203:1-505203:8.

14. HERA, Tetra acetyl ethylene diamine (TAED) CAS 10543-57-4 Human \& Environmental Risk Assessment on Ingredients of European Household Cleaning Products 2002, 1-71.

15. P. Sofokleous, S. Ali, P. Wilson, A. Buanz, S. Gaisford, D. Mistry, A. Fellows and R. M. Day, Acta Biomater., 2017, 64, 301-312.

16. K. Liu, X. Zhang and K. Yan, Cellulose, 2017, 24, 1555-1561.

17. R. Warburton, Peracetic Acid in the Fresh Food Industry, Food Safety Magazine, June 2014.

18. M. Kitis, Environ. Int., 2004, 30, 47-55.

19. W. A. Rutala and D. J. Weber, Disinfection, Sterilization and Control of Hospital Waste, 8th Ed., 2015.

20. B. Becker, F. H. H. Brill, D. Todt, E. Steinmann, J. Lenz, D. Paulmann, B. Bischoff and J. Steinmann, Antimicrob. Resist. Infect. Control, 2017, 6, 1-6.

21. B. Ghimire, E. J. Szili, B. L. Patenall, P. Lamichhane, N. Gaur, A. J. Robson, D. Trivedi, N. T. Thet, A. T. A. Jenkins, E. H. Choi and R. D. Short, Plasma Sources Sci. Technol., 2021, 30, 035009-1:035009-15.

22. B. Ghimire, J. Sornsakdanuphap, Y. J. Hong, H. S. Uhm, K. D. Weltmann and E. H. Choi, Physics of Plasmas, 2017, 24, 
073502:1-073502:12.

23. A. J. Wu, H. Zhang, X. D. Li, S. Y. Lu, C. M. Du and J. H. Yan, IEEE Transactions on Plasma Science, 2015, 43, 836845.

24. G. Jentsch, Bacteriocidal washing agents contain. a per-compound and TAED:PAG mixture, US patent-US5021182A, 1991. 


\section{Supplementary Material}

On-demand cold plasma activation of acetyl donors for bacteria and virus decontamination

Endre J. Szili ${ }^{a^{\dagger}}$, Bhagirath Ghimire ${ }^{b^{\dagger}}$, Bethany Lee Patenall ${ }^{c}$, Mohammed Rohaim ${ }^{d}$, Dharmit Mistry ${ }^{e}$, Adrian Fellows ${ }^{e}$, Muhammad Munir ${ }^{d}$, A. T. A. Jenkins ${ }^{c}$, Rob D. Short ${ }^{a, b}$

${ }^{a}$ Future Industries Institute, University of South Australia, Adelaide SA 5095, Australia

${ }^{b}$ Department of Chemistry and Material Science Institute, Lancaster LA1 4YB, United Kingdom

'Department of Chemistry, University of Bath, Bath BA2 7AY, United Kingdom

${ }^{\mathrm{d} D i v i s i o n}$ of Biomedical and Life Sciences, Lancaster University, Lancaster LA1 4YW, United Kingdom

eGAMA Health Care Ltd, 2 Regal Way, Watford WD24 4YJ, United Kingdom

+ Equal co-first authors.

\section{Table of contents}

S1: Measurement and calculation of cold plasma jet dissipated power ............................................. 2

S2: Optical emission spectrum from the cold plasma jet ................................................................

S3: Measurement of $\mathrm{H}_{2} \mathrm{O}_{2}$ and PAA after plasma activation of DIW/acetyl donors............................ 3

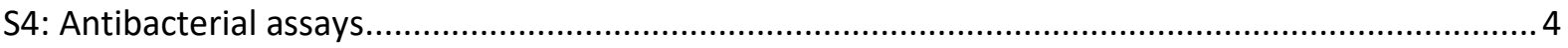

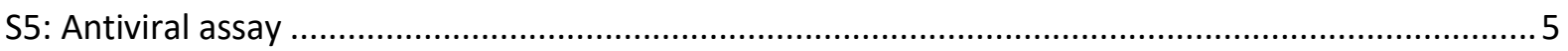

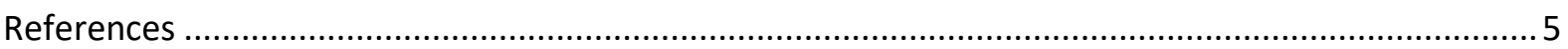




\section{S1: Measurement and calculation of cold plasma jet dissipated power}

The schematic of the experimental setup showing the locations for measuring voltage and current signals is presented in Fig. S1. Plasma was generated by using a commercially available PVM5004000 alternating current (AC) power supply ${ }^{1}$. AC power supply was used in this study as the breakdown voltage and energy consumption in the discharge is known to be lower than the direct current (DC) discharge ${ }^{2}$. The gap distance $(\mathrm{g})$ between the end of the quartz tube and target liquid was set to $4 \mathrm{~mm}$. Voltage signals were measured using a PINTEK HVP-39 pro high voltage probe (Pingtek Electronics Co. Ltd) and current signals were measured using a Pearson current probe (Pearson Electronics Inc., model 2877). Both signals were measured at the high voltage cable (Fig. 2(b) in manuscript) and were recorded on a Siglent SDS1102CML oscilloscope (Siglent Technologies Co. $L t d)$. The total dissipated power (P) was calculated as $^{3}$ :

$\mathrm{P}=f \int_{t=0}^{t=T} I(t) V(t) d t-------------(S 1)$

where, $I(t)$ and $V(t)$ represent the instantaneous values of current and voltage at a time ' $t$ '. The frequency (f) of the discharge was $23.5 \mathrm{kHz}$. Using equation (S1), the total dissipated power was calculated to be $\sim 2.71 \mathrm{~W}$.

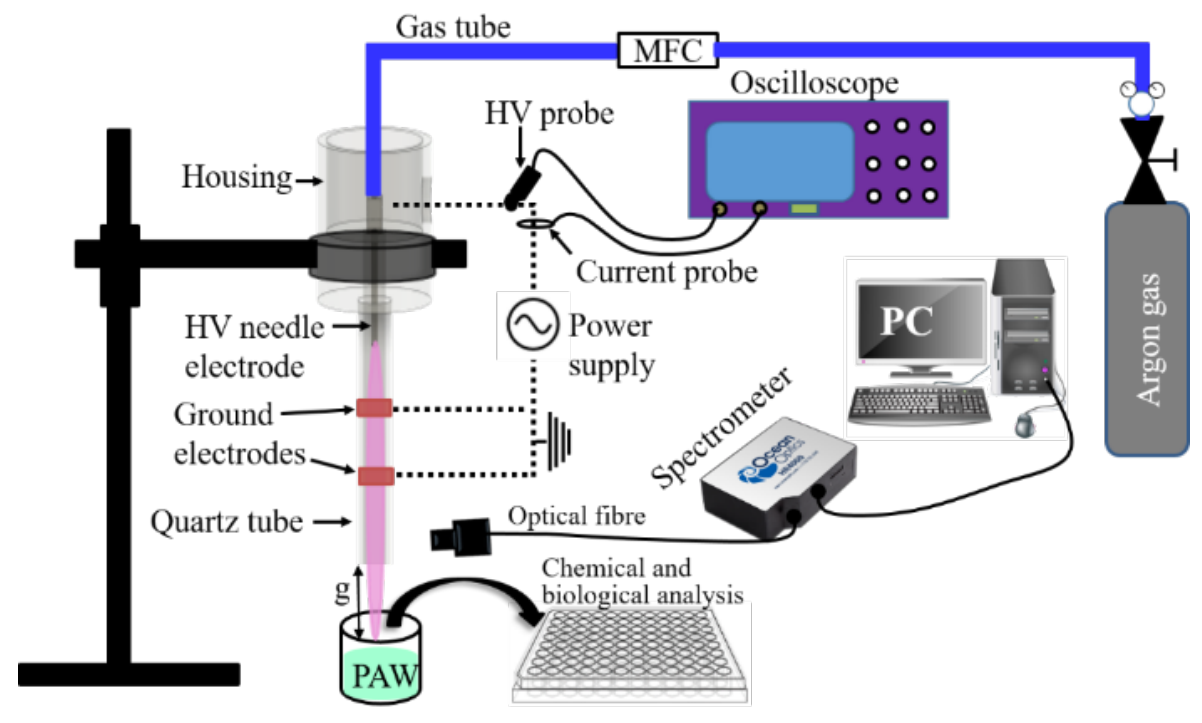

Fig. S1: Schematic of the experimental setup

\section{S2: Optical emission spectrum from the cold plasma jet}

The technique of optical emission spectroscopy (OES) can be used to identify the excited species including the short-lived reactive oxygen / nitrogen species generated during the discharge. Optical emission signals were measured at a $3 \mathrm{~mm}$ position below the end of the quartz tube and recorded using a factory calibrated HR4000-CG-UVNIR spectrometer (Ocean Optics Inc., resolution: $0.47 \mathrm{~nm}$ ) 
with an optical fibre of diameter $600 \mu \mathrm{m}$. The integration time in the spectrometer was set to 70 milliseconds. The typical OES signal of the Ar discharge is presented in Fig. 2(c) in the manuscript. A strong emission from the hydroxyl radical $\left({ }^{\circ} \mathrm{OH}\right)$ occurs at $309 \mathrm{~nm}$. The ${ }^{\bullet} \mathrm{OH}$ is a precursor for the formation of $\mathrm{H}_{2} \mathrm{O}_{2}$. Emissions from excited nitrogen (nitrogen second positive system $\left(\mathrm{N}_{2} \mathrm{SPS}\right)$ and nitrogen first negative system ( $N_{2}$ FNS) occur at several wavelengths ( $296 \mathrm{~nm}, 311 \mathrm{~nm}, 315 \mathrm{~nm}, 336$ $\mathrm{nm}, 357 \mathrm{~nm}, 380 \mathrm{~nm}, 391 \mathrm{~nm}$, etc.) and are also responsible for the formation of the ${ }^{\circ} \mathrm{OH}$ through collision with ambient water molecules ${ }^{4,5}$. The region from $600-900 \mathrm{~nm}$ is dominated by excited argon species, and they also play a major role in the formation of the ${ }^{\circ} \mathrm{OH}$.

\section{S3: Measurement of $\mathrm{H}_{2} \mathrm{O}_{2}$ and PAA after plasma activation of DIW/acetyl donors}

The concentration of $\mathrm{H}_{2} \mathrm{O}_{2}$ in the plasma activated water / acetyl donor solutions was measured using a commercially available o-phenylenediamine (OPD, CAS number: 95-54-5, SigmaAldrich Corporation) and horseradish peroxidase (HRP, CAS number: 9003-99-0, SigmaAldrich Corporation) detection system. In the presence of $\mathrm{HRP}, \mathrm{OPD}$ reacts with $\mathrm{H}_{2} \mathrm{O}_{2}$ to form 2-3-diaminophenazine with an absorbance maximum of $450 \mathrm{~nm}$ that can be measured spectrophotometrically. A tablet of OPD was dissolved in $10 \mathrm{~mL}$ of DIW and $20 \mu \mathrm{L}$ of $2 \mathrm{mg} / \mathrm{mL}$ HRP was added into the solution. A $5 \mu \mathrm{L}$ volume of PA-DIW, PA-TP (or different concentrations of $\mathrm{H}_{2} \mathrm{O}_{2}$, CAS number: 7722-84-1, SigmaAldrich) were added into wells of a 96-well plate containing $195 \mu \mathrm{L}$ of the OPD / HRP solution and incubated for 15 minutes at ambient temperature in the dark. The absorbance values were measured with a plate reader (Synergy LX, Biotek) at $\lambda=450 \mathrm{~nm}$. The absorbance reading is proportional to the concentration of $\mathrm{H}_{2} \mathrm{O}_{2}$ and the obtained line of best fit [Fig. S2] was used to estimate the $\mathrm{H}_{2} \mathrm{O}_{2}$ concentration formed in the PA-DIW and PA-TP.

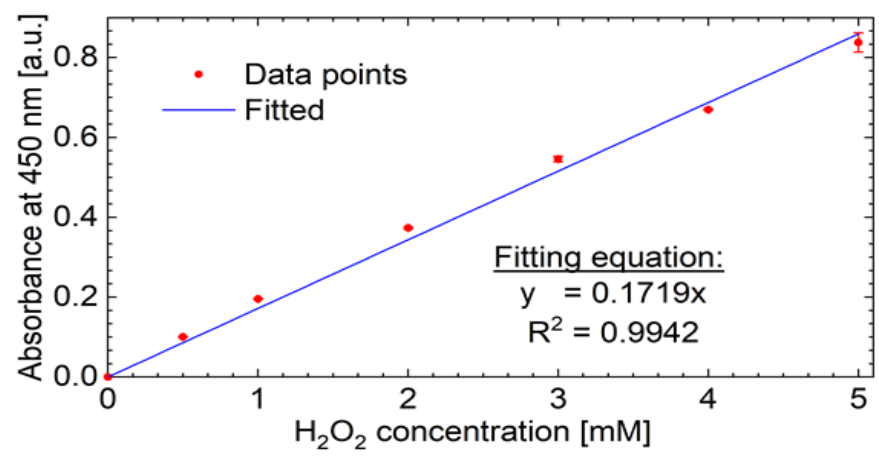

Fig. S2: Calibration curve used to measure the concentration of $\mathrm{H}_{2} \mathrm{O}_{2}$ in PA-DIW and PA-TP.

Measurement of the PAA concentration in the PA-TP was performed using the following reagents: (a) potassium iodide (CAS number: 7681-11-0, Sigma Aldrich), (b) catalase (CAS number: 9001-05-02, Sigma Aldrich), (c) TAED (CAS number: 10543-57-4, Sigma Aldrich), (d) PAG (CAS number: 604-68-2, Sigma Aldrich), and (e) PAA (Product code: 10302633, Fisher Scientific). Any $\mathrm{H}_{2} \mathrm{O}_{2}$ present in the PADIW or PA-TP is quenched by catalase and remaining species (mainly PAA in PA-TP) result in the 
oxidation of $\mathrm{KI}$ at $350 \mathrm{~nm}$. To verify this principle, we first studied the inhibition of different concentrations of $\mathrm{H}_{2} \mathrm{O}_{2}$ (Fig. 4 in manuscript) with catalase. The $\mathrm{H}_{2} \mathrm{O}_{2}$ concentrations used in this experiment $(0.6-10 \mathrm{mM})$ were within the same $\mathrm{H}_{2} \mathrm{O}_{2}$ concentration range present in the PA-DIW or PA-TP (Fig. 3 in manuscript). The protocol used to obtain Fig. 4 in the manuscript involved mixing different concentrations of $\mathrm{H}_{2} \mathrm{O}_{2}$ (volume: $100 \mu \mathrm{L}$ ) in either $100 \mu \mathrm{L}$ of DIW (without catalase) or with catalase (concentration: $75 \mathrm{mg} / \mathrm{mL}$, volume: $100 \mu \mathrm{L}$ ) in an Eppendorf tube. This mixture was incubated for 15 minutes at room temperature. Afterwards, $20 \mu \mathrm{L}$ of the solution was transferred to $180 \mu \mathrm{L}$ of $100 \mathrm{mM} \mathrm{KI}$ and the solution was incubated for an additional 15 minutes in the dark before measuring the absorbance ( $\lambda=350 \mathrm{~nm}$, Synergy LX, Biotek).

The PAA concentration in the PA-TP was determined using a calibration curve of the PAA induced oxidation of KI. PAA in aqueous solution is known to dissociate into acetic acid $\left(\mathrm{CH}_{3} \mathrm{COOH}\right)$ and $\mathrm{H}_{2} \mathrm{O}_{2}$. It was confirmed that $\mathrm{CH}_{3} \mathrm{COOH}$ does not contribute to the oxidation of $\mathrm{KI}$ in our experiments, and that the use of $75 \mathrm{mg} / \mathrm{mL}$ catalase quenches all $\mathrm{H}_{2} \mathrm{O}_{2}$ in the dissociated PAA solution. The calibration curve was constructed by first preparing different concentrations of PAA $(0.5 \mathrm{mM}-8 \mathrm{mM})$. The diluted PAA solutions (volume: $100 \mu \mathrm{L}$ ) were mixed with catalase (concentration: $75 \mathrm{mg} / \mathrm{mL}$, volume: $100 \mu \mathrm{L}$ ) in an Eppendorf tube and incubated for 15 minutes. Afterwards, $20 \mu \mathrm{L}$ of the liquid from the mixture was transferred to $180 \mu \mathrm{L}$ of $100 \mathrm{mM} \mathrm{KI}$ and the solution was incubated for an additional 15 minutes before measuring the absorbance at $350 \mathrm{~nm}$. The resulting calibration curve is shown in Fig. $\mathbf{S 3}$.

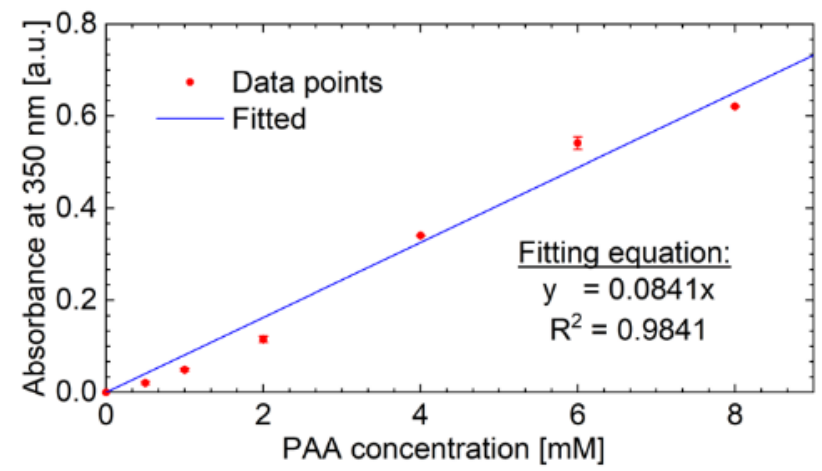

Fig. S3: Calibration curve used to measure the concentration of PAA in PA-DIW and PA-TP.

\section{S4: Antibacterial assays}

Staphylococcus aureus (H560) and Pseudomonas aeruginosa (PAO1) were grown in $10 \mathrm{~mL}$ of tryptic soy broth (TSB) and Luria-Bertani (LB) broth, respectively, at $37^{\circ} \mathrm{C}$ for $18 \mathrm{~h}$. The cultures were spun at $10000 \mathrm{rpm}$ and washed and resuspended in phosphate buffered saline (PBS). $10 \mathrm{~mL}$ of overnight culture was then added into $10 \mathrm{~mL}$ of bacterial broth to make a subculture ( $\left.2 \times 10^{6} \mathrm{CFU} / \mathrm{mL}\right) .100 \mu \mathrm{L}$ volume aliquots of the bacteria subculture were added into wells of a 96-well plate followed by addition of $100 \mu \mathrm{L}$ of the "test" solutions (PA-DIW, PA-TP) (to achieve a 1:2 dilution). Further 1:2 
dilution of the test solutions was carried out using the bacteria subculture solution to achieve a final dilution of 1:4. Bacteria were grown statically for $18 \mathrm{~h}$ at $37^{\circ} \mathrm{C}$. Absorbance was recorded at $600 \mathrm{~nm}$ which corresponded to solution turbidity that is directly related to the concentration of bacteria. Bacterial growth was assessed relative to the negative control sterile broth.

\section{S5: Antiviral assay}

All experiments using SARS-CoV-2 were performed in a Biosafety Level 3 Facility at The Lancaster University. The SARS-CoV-2 was propagated in Vero-E6 cells (African green monkey kidney) constitutively expressing human angiotensin-converting enzyme 2 (ACE2) receptors as described by Pyke et $a^{6}$. These cells were maintained in Dulbecco's modified Eagle medium (DMEM) supplemented with $10 \%$ heat-inactivated foetal calf serum (FCS), $100 \mathrm{U}$ of penicillin and $100 \mathrm{~g}$ of streptomycin per $\mathrm{mL}$ and incubation at $37^{\circ} \mathrm{C}$ with $5 \% \mathrm{CO}_{2}$. A plaque assay was used to quantify the virus titre from three independent experiments. The "test" solutions were diluted 1:2 (50 $\mu \mathrm{L}$ of PADIW or PA-TP in $50 \mu \mathrm{L}$ DIW) and mixed with $50 \mu \mathrm{L}$ of viral inoculum (maintained at a concentration of $1 \times 10^{6} \mathrm{PFU} / \mathrm{mL}$ ) to achieve a final dilution of $1: 4$ of the test solutions. Afterwards, the solutions were incubated at room temperature for 15 minutes. The virus-test solution mixtures were mixed by pipetting up and down several times, and titrated using 10-fold serial dilutions (3 replicates of each) in 12-well culture plates seeded with confluent monolayers of Vero-E6 cells in FCS-free medium, and then incubated for $1 \mathrm{~h}$ at $37^{\circ} \mathrm{C}$. Afterwards, cells were washed twice with PBS before adding $2 \mathrm{X}$ modified eagle's medium (MEM)+4\% fetal bovine serum (FBS) containing $2 \%$ methylcellulose and incubated at $37^{\circ} \mathrm{C} .72 \mathrm{~h}$ hours post infection, the media was removed, and cells were washed with PBS. Cells were fixed in 4\% paraformaldehyde for $1 \mathrm{~h}$ at room temperature. Cells were stained with $0.3 \%$ crystal violet in distilled water to visualise and count the plaques.

\section{References}

1 https://www.amazing1.com/hv-hf-power-supplies.html, accessed June 2021.

2 P. Lamichhane, R. Paneru, L. N. Nguyen, J. S. Lim, P. Bhartiya, B. C. Adhikari, S. Mumtaz and E. H. Choi, React. Chem. Eng., 2020, 5, 2053-2057.

B. Ghimire, E. J. Szili, P. Lamichhane, R. D. Short, J. S. Lim, P. Attri, K. Masur, K. D. Weltmann, S. H. Hong and E. H. Choi, Appl. Phys. Lett., , DOI:10.1063/1.5086522.

4 B. Ghimire, E. J. Szili, B. L. Patenall, P. Lamichhane, N. Gaur, A. J. Robson, D. Trivedi, N. T. Thet, A. T. A. Jenkins, E. H. Choi and R. D. Short, Plasma Sources Sci. Technol., 2021, 30, 035009-1:035009-15.

5 A. Khlyustova, C. Labay, Z. Machala, M. P. Ginebra and C. Canal, Front. Chem. Sci. Eng., 2019, 13, $238-252$.

6 A. Pyke et al., Culture of the severe acute respiratory syndrome coronavirus 2 (SARS-CoV-2; f.2019-nCoV) https://www.protocols.io/view/culture-of-the-severe-acute-respiratory-syndrome-c-bcduis6w, accessed June 2021. 